\title{
Bond-Strengthening Hooks for RC Members with 1300 MPa-Class Shear-Reinforcing Spirals
}

\author{
Yuichi Sato*1, Katsuhiro Nagatomo ${ }^{2}$ and Yoshifumi Nakamura ${ }^{3}$

\begin{abstract}
${ }^{1}$ Research Associate, Department of Urban Environment Engineering, Kyoto University, Japan
${ }^{2}$ Professor, Department of Civil Engineering, Takamatsu National College of Technology, Japan
\end{abstract} \\ ${ }^{3}$ General Manager, Osaka Branch, Neturen Corporation, Japan
}

\begin{abstract}
This paper presents an experimental investigation of bond-strengthening hooks as a new method to increase bond strength along flexural reinforcing bars in reinforced concrete (RC) beams and columns. The RC members, which consist of 1,300 MPa-class spirals as shear reinforcement, often suffer from bond splitting failure. The proposed method attempts to increase confining stiffness around the flexural bars by placing U-shaped hooks and to prevent premature bond splitting failure. Twelve specimens with varied amounts and sizes of the hooks were prepared to verify the strengthening effectiveness under monotonic and cyclic loading conditions. The test result indicated that the hooks increased the bond strength along the flexural bars although the strengthening effectiveness was limited by effective reinforcement ratio $p_{b e}$. This limit is determined by size of stresstransmitting zones of concrete around anchors of the hooks. Anchors of the hooks are recommended to be longer than twelve times the hook diameter and inserted deeper than a quarter of the member depth $(D / 4)$. Proposed design equations provided modest estimates of the shear strengths.
\end{abstract}

Keywords: reinforced concrete; beam; column; shear strength; bond strength; bond-strengthening hook; 1300 MPa-class spiral

\section{Introduction}

Ultra high strength spiral provides large shear capacity to a RC member without congestion due to overreinforcement. The spirals are especially effective for members of high-rise RC buildings where large flexural and shear capacities are required. Reduction of amount of shear reinforcement, however, often accompanies with reduction of bond strength along flexural reinforcing bars. Figure 1 compares two column specimens in a previous work (Sato et al. 2003): Specimen K1 consisted of a 1,300 MPa-class spiral while K2 was reinforced with larger amount of normal strength ties. Specimens $\mathrm{K} 1$ and $\mathrm{K} 2$ possessed an equivalent shear reinforcement level in term of $p_{w} \sigma_{w y}$ by $7.4 \mathrm{MPa}$ to $7.8 \mathrm{MPa}$, where $p_{w}$ $=$ shear reinforcement ratio, and $\sigma_{w y}=$ yield stress of shear reinforcing bar. Nevertheless, Specimen K1 resulted in a remarkably inferior ductility in comparison with K2. The deterioration of Specimen K1 was caused by bond splitting failure along the flexural bars as crack pattern in Fig. 1 shows. The comparison between Specimens $\mathrm{K} 1$ and $\mathrm{K} 2$ indicates that the bond strength along the flexural bars depends on rather stiffness of the lateral reinforcement than the reinforcement's strength.

*Contact Author: Yuichi Sato, Research Associate,

Department of Urban Environment Engineering, Kyoto University

Yoshidahonmachi, Sakyo-ku Kyoto 606-8501 Japan

Tel: +81(0)75-753-5735 Fax: +81(0)75-753-5748

e-mail: satou@archi.kyoto-u.ac.jp

(Received April 14, 2003 ; accepted September 1, 2003 )
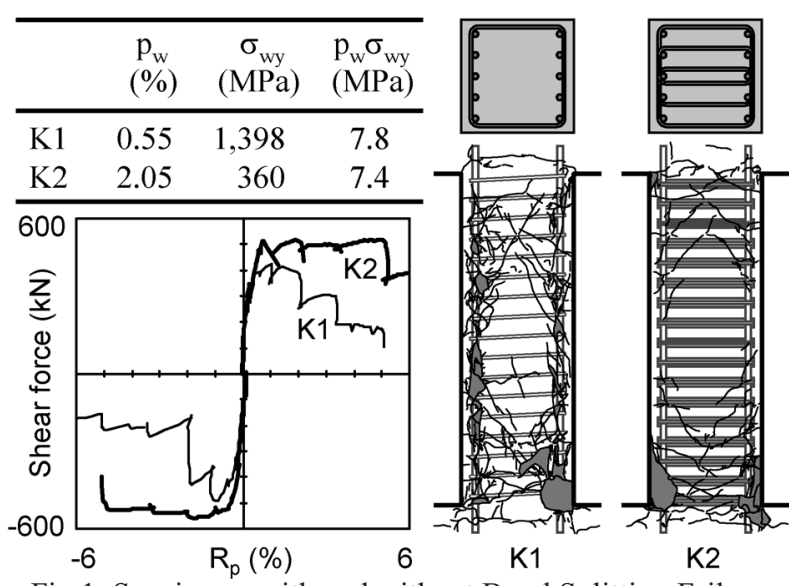

Fig.1. Specimens with and without Bond Splitting Failure

According to AIJ's Guidelines (AIJ 1999), the shear strength $V_{u}$ is given by Eqs. (1)-(10).

$$
\begin{aligned}
V_{u}= & \min \left(V_{u 1}, V_{u 2}, V_{u 3}, V_{b u}\right) \\
V_{u 1}= & p_{w} \sigma_{w y} b_{e} j_{e} \cot \phi \\
& +\left(v \sigma_{B}-\frac{5 p_{w} \sigma_{w y}}{\lambda}\right) \frac{b D}{2} \tan \theta \\
V_{u 2}= & \frac{\lambda v \sigma_{B}+p_{w} \sigma_{w y}}{3} b_{e} j_{e}
\end{aligned}
$$




$$
\begin{aligned}
V_{u 3} & =\frac{\lambda v \sigma_{B}}{2} b_{e} j_{e} \\
V_{b u} & =j_{e} \tau_{b u} \Sigma \psi+\left(v \sigma_{B}-\frac{2.5 \tau_{b u} \Sigma \psi}{\lambda b_{e}}\right) \frac{b D}{2} \tan \theta
\end{aligned}
$$

where

$$
\begin{aligned}
& p_{w}=\pi N_{w} d_{b w}^{2} /\left(4 b_{e} s_{w}\right) \\
& \cot \phi=2-20 R_{p} \\
& v \quad=\text { effective concrete strength factor } \\
& =\left(1-20 R_{p}\right)\left(0.7-\sigma_{B} / 200\right) \\
& \tan \theta=\sqrt{(L / D)^{2}+1}-L / D \\
& \lambda=\text { effective area factor for truss action } \\
& =1-s_{w} /\left(2 j_{e}\right)-b_{s} /\left(4 j_{e}\right) \\
& b \quad=\text { width of member; } \\
& b_{e} \quad=\text { effective width of member (= width of }
\end{aligned}
$$

Equations (2), (3) and (4) give the strengths determined by amount and strength of shear reinforcement, concrete strength and member geometry. However, a smaller spiral ratio $p_{w}$ reduces bond strength along the longitudinal bar $\tau_{b u}$. The reduction of the $\tau_{b u}$ results in a smaller tensile force in the spiral and a smaller compressive force in the concrete strut as illustrated in Fig.2.

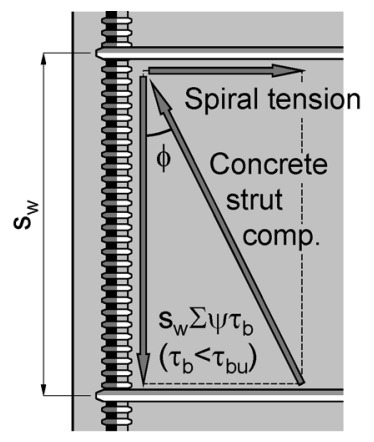

(a) Equilibrium in Eqs.(2)-(4)

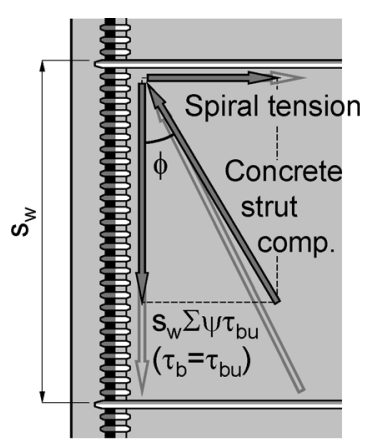

(b) Equilibrium in Eq.(5)
Fig.2. Limit of Stress-transmission due to Bond Strength Reduction
Equation (5) defines a shear strength limited by the bond strength $\tau_{b u}$. The $\tau_{b u}$ is given by Eqs. (11)-(19).

$$
\begin{aligned}
\tau_{b u} \quad & =\beta_{p} \alpha_{t}\left(\tau_{c}+\tau_{s}\right) \\
\beta_{p} & =1-10 R_{p} \\
\alpha_{t} & =0.75+\sigma_{B} / 400 \quad \text { for top bar in a beam } \\
& =1 \\
\tau_{c} \quad & =\left(0.085 b_{i}+0.1\right) \sqrt{\sigma_{B}} \\
\tau_{s} \quad & =\left(54+45 N_{w} / N_{t}\right)\left(b_{s i}+1\right) p_{w} \\
=36.5 & \pi d_{b w}{ }^{2} /\left(s_{w} d_{b t}\right) \quad \text { for } b_{s i}>b_{c i} \\
b_{i} & =\text { min }\left(b_{s i}, b_{c i}\right) \\
b_{s i} & =\text { coefficient for side splitting mode } \\
& =b /\left(N_{t} d_{b t}\right)-1 \\
b_{c i} & =\text { coefficient for corner splitting mode } \\
& =\sqrt{2}\left(d_{c w}+d_{c d}-d_{b t}\right) / d_{b t}-1 \\
\text { where } & \\
d_{b t} & =\text { diameter of flexural bar; } \\
d_{c d} & =\text { thickness of cover in depth direction; } \\
d_{c w} & =\text { thickness of cover in width direction; and } \\
N_{t} & =\text { number of flexural bars in a layer. }
\end{aligned}
$$

The Guidelines adopt an assumption that the $\tau_{b u}$ comprises contributions of concrete $\tau_{c}$ and steel $\tau_{s}$. The latter is further classified into two cases according to the bond failure modes. The coefficient $b_{i}$ defined in Eq. (17) represents the failure mode, which is the smaller between $b_{s i}$ given by Eq. (18) and $b_{c i}$ by Eq. (19). The side splitting mode $\left(b_{s i}<b_{c i}\right)$ is usually a case in a member with heavy flexural reinforcement, where adjacent longitudinal bars are arranged with small spacings. Equation (15) gives steel contribution to the $\tau_{b u}$ in the case of side splitting mode. It takes account of the effectiveness of the shear reinforcement by the crosssectional area ratio $p_{w}$, not by the $p_{w} \sigma_{w v}$ term.

Figure 3 illustrates application of UU-shaped hook as one of the possible methods to increase the bond strength, which saves cost and labor (Kamitani et al. 2002). The hooks can be applied after completion of arrangement of flexural and shear reinforcements. In addition, the hooks are made of inexpensive normal strength steel and can be easily formed into the shape. The bondstrengthening method proposed herein will therefore achieve increase of shear and bond capacities at a lower cost, avoiding a congested bar arrangement.

This paper presents an experimental study to verify effectiveness of the bond-strengthening hooks with varied amounts and shapes. The test results showed that the hooks increase the bond strength and keep the RC beams and columns from premature shear failure under monotonic and even cyclic loading conditions.

Through the test, this paper discusses the influences of the amounts and the shapes of the hooks on the bond 
strength $\tau_{b u}$. The effective concrete strength factor $v$ will be defined as a function of only concrete strength $\sigma_{B}$ (AIJ 1999) although the actual strength is influenced by the reinforcement (Sato 2002).

\section{Experimental Program}

Twelve specimens were prepared, which consisted of 1,300 $\mathrm{MPa}$-class spirals as shear reinforcement. Eight of them belonged to $\mathrm{N}$ series (Table 1) while the rest to $\mathrm{H}$ series (Table 2). Figure 4 illustrates geometries of the specimens and Fig. 5 test apparatus. Strains in the reinforcements were measured with strain gauges (SG). Table 3 shows the material properties.

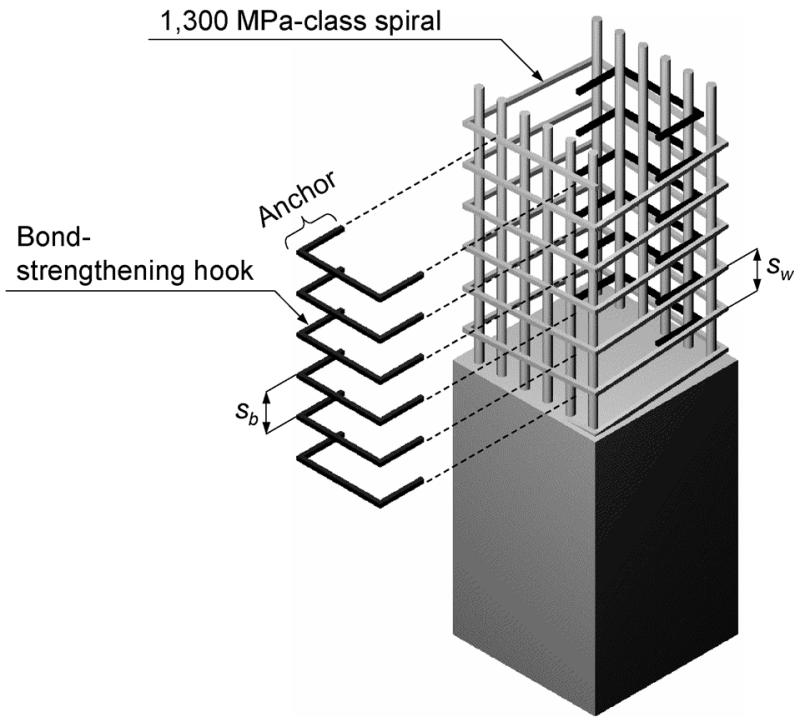

Fig.3. Bond-strengthening Hook
The $\mathrm{N}$ series represented beams with relatively light shear reinforcement $\left(p_{w}=0.29 \%\right)$ and normal concrete strength $\left(\sigma_{B}=35.7 \mathrm{MPa}\right)$. The specimens have span length of $900 \mathrm{~mm}$, and are $300 \mathrm{~mm}$ deep and $300 \mathrm{~mm}$ wide. The shear span to depth ratio $a / D$ is 1.5 . The flexural reinforcement consists of twelve steel bars with diameter of $16 \mathrm{~mm}$.

The H series represented columns at lower stories of high-rise RC buildings. The specimens therefore consisted of heavier shear reinforcement $\left(p_{w}=0.55 \%\right)$ and concrete with higher strength $\left(\sigma_{B}=45.1 \mathrm{MPa}\right)$.

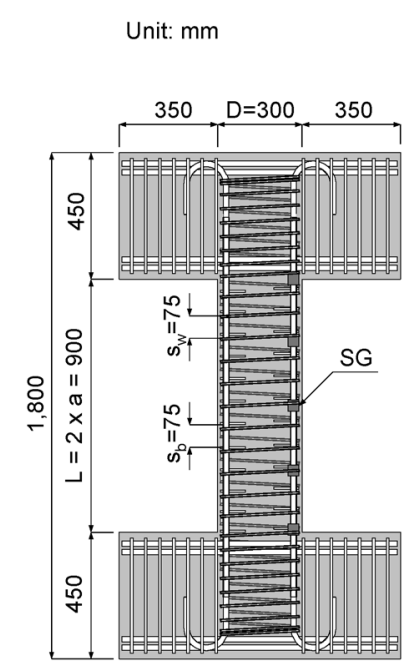

(a) $\mathrm{N}$ series

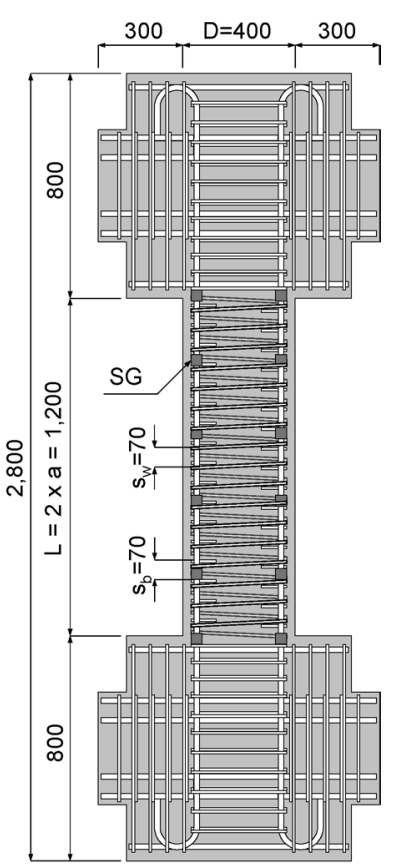

(b) $\mathrm{H}$ series
Fig.4. Specimens

Table 1. Cross-sections of N Series Specimens

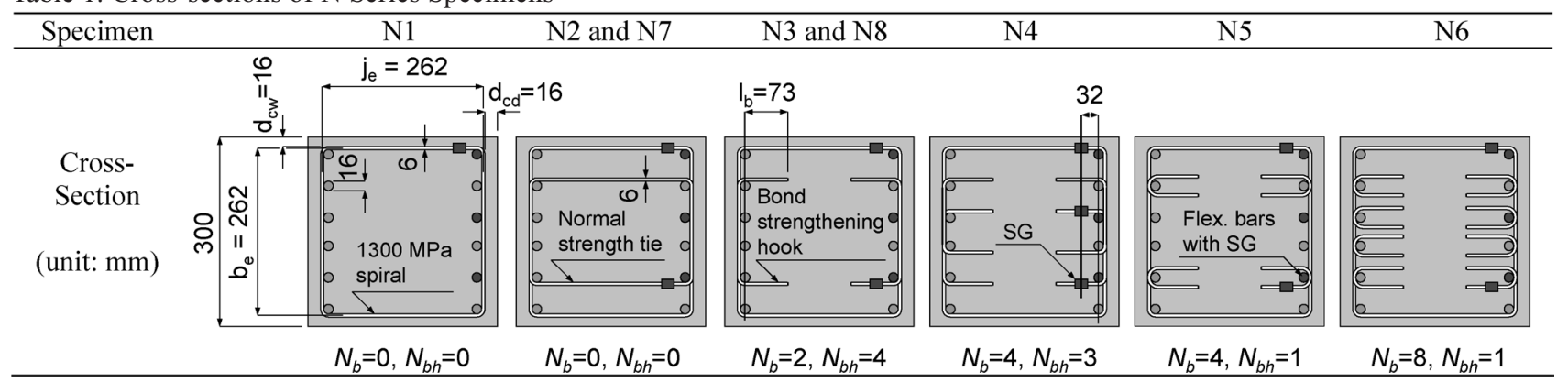

Table 2. Cross-sections of H Series Specimens

\begin{tabular}{llll}
\hline Specimen & $\mathrm{H} 0$ & H6C \\
\hline $\begin{array}{c}\text { Cross- } \\
\text { section } \\
\text { (unit: } \mathrm{mm} \text { ) }\end{array}$
\end{tabular}




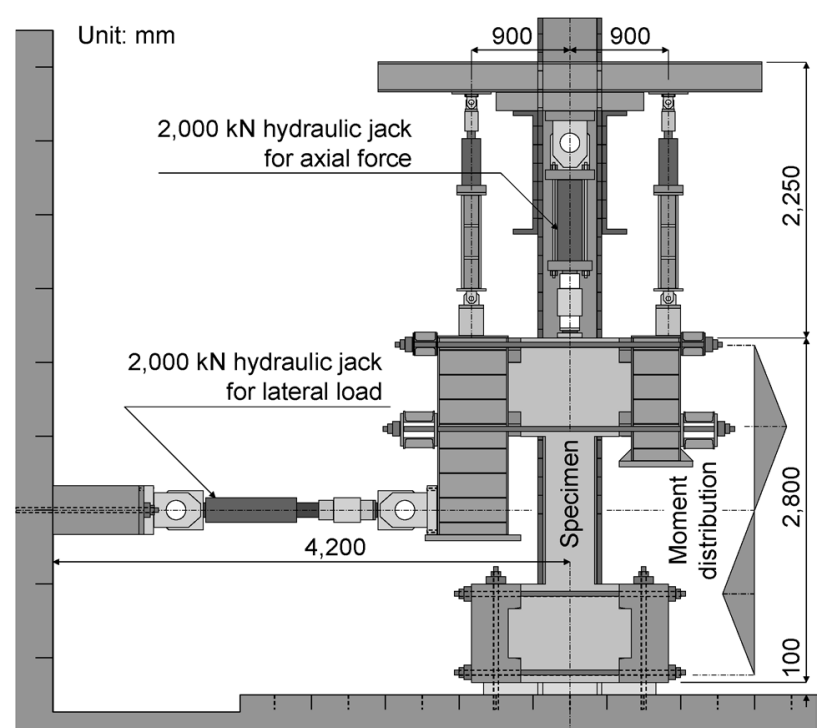

Fig.5. 5 Test Setup (H series)

Table 3. Material Properties

\begin{tabular}{llcccc}
\hline \multicolumn{2}{c}{ Specimen } & $\mathrm{N} 1-\mathrm{N} 6$ & $\mathrm{~N} 7, \mathrm{~N} 8$ & $\mathrm{H} 0-\mathrm{H} 8$ & $\mathrm{H} 6 \mathrm{C}$ \\
\hline$\sigma_{B}$ & $(\mathrm{MPa})$ & 35.7 & 35.7 & 45.1 & 45.1 \\
\cline { 3 - 6 }$\varepsilon_{c}$ & $\left(\mathbf{x 1 0 ^ { - 3 }}\right)$ & --- & --- & 2.76 & 2.76 \\
\cline { 3 - 6 }$\sigma_{t y}$ & $(\mathrm{MPa})$ & 837 & 360 & 860 & 400 \\
\cline { 3 - 6 }$\sigma_{t u}$ & $(\mathrm{MPa})$ & 916 & 499 & 966 & 588 \\
\cline { 3 - 6 }$E_{s t}$ & $(\mathrm{GPa})$ & 183 & 179 & 157 & 159 \\
\cline { 3 - 6 }$\sigma_{w y}$ & $(\mathrm{MPa})$ & 1,378 & 1,378 & 1,398 & 1,398 \\
\cline { 3 - 6 }$\sigma_{w u}$ & $(\mathrm{MPa})$ & 1,391 & 1,391 & 1,481 & 1,481 \\
$E_{s w}$ & $(\mathrm{GPa})$ & 181 & 181 & 194 & 194 \\
$\sigma_{b y}$ & $(\mathrm{MPa})$ & 305 & 305 & 409 & 409 \\
$\sigma_{b u}$ & $(\mathrm{MPa})$ & 452 & 452 & 500 & 500 \\
\cline { 3 - 6 }$E_{s b}$ & $(\mathrm{GPa})$ & 185 & 185 & 168 & 168 \\
\hline
\end{tabular}
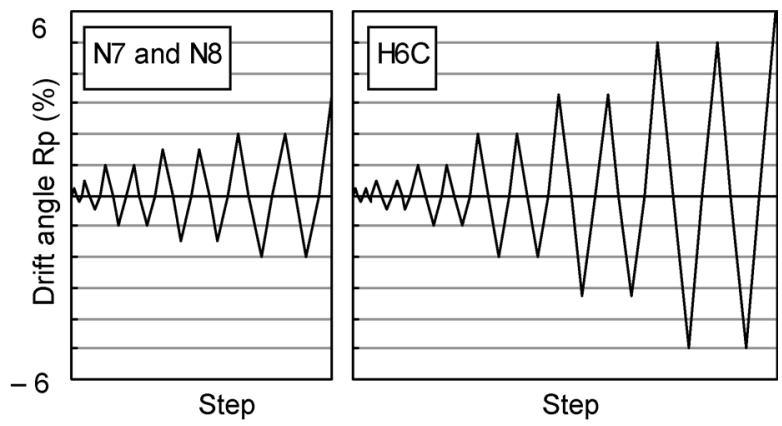

Fig.6. Cyclic Load Patterns
The span, depth and width were enlarged up to 1200 $\mathrm{mm}, 400 \mathrm{~mm}$ and $400 \mathrm{~mm}$, respectively. The $a / D$ is 1.5 and axial force ratio $N /\left(b D \sigma_{B}\right)$ is 0.15 . Twelve bars with diameter of $19 \mathrm{~mm}$ were provided as flexural reinforcement.

Specimens N1, N2, N3, N4, N5, N6, H0, H4 and H8 were subjected to monotonic loads. These specimens consisted of flexural bars with yield stress around 850 $\mathrm{MPa}$ in an attempt to induce shear failure before flexural yielding. The specimens contain varied numbers and widths of the bond-strengthening hooks made of normal strength steel with diameter of $6 \mathrm{~mm}$. The $N_{b}$ is defined as the total of anchors of the hooks (Fig. 3) in a side of a specimen. The $N_{b h}$ is number of the flexural bars contacting with a hook, and indirectly indicates the width of the hook.

The anchor length $l_{b}$, which is distance between centroid of the flexural bar and end of the anchor, was determined according to two requirements by the AIJ. Firstly, Recommendation for Detailing and Placing of Concrete Reinforcement (AIJ 1986) requires twelve times the bar diameter as the anchor length. Secondly, the Inelastic Displacement Concept Guidelines (AIJ 1999) require bond strengthening along flexural bars in a zone within D/4-deep from the member surface. The $l_{b}$ was thus determined around $70 \mathrm{~mm}$.

Equation (20) gives cross-sectional area ratio of the hooks $p_{b}$.

$$
p_{b}=\pi N_{b} d_{b b}^{2} /\left(4 b_{e} s_{b}\right)
$$

where

$$
d_{b b}=\text { diameter of bond-strengthening hook; and }
$$$$
s_{b} \quad=\text { spacing of bond-strengthening hooks. }
$$

Specimens N2 and N7 contain no hook, but a set of closed tie made of normal strength steel instead. The $N_{b}$ and the $N_{b h}$ of N2 and N7 were therefore 0 and 0 , respectively.

Specimens N7, N8 and H6C were subjected to cyclic loads. Ratio of shear strength $V_{u}$ to flexural strength $V_{y}$ of a member in an actual building is usually larger than 1.0. For this reason, the specimens consisted of flexural bars with lower yield stresses (360 MPa or $400 \mathrm{MPa}$ ) in order to reduce $V_{y}$. Figure 6 shows the applied cyclic load patterns.

Table 4. Reinforcement Ratio, Shear Strengths and Bond Strengths

\begin{tabular}{llcccccccccccc}
\hline Specimen & & $\mathrm{N} 1$ & $\mathrm{~N} 2$ & $\mathrm{~N} 3$ & $\mathrm{~N} 4$ & $\mathrm{~N} 5$ & $\mathrm{~N} 6$ & $\mathrm{~N} 7$ & $\mathrm{~N} 8$ & $\mathrm{H} 0$ & $\mathrm{H} 4$ & H8 & H6C \\
\hline$p_{b}$ & $(\%)$ & 0.00 & 0.00 & 0.29 & 0.58 & 0.58 & 1.15 & 0.00 & 0.29 & 0.00 & 0.49 & 0.99 & 0.74 \\
$p_{w}\left(\sigma_{w y}>1,300 \mathrm{MPa}\right)$ & $(\%)$ & 0.29 & 0.29 & 0.29 & 0.29 & 0.29 & 0.29 & 0.29 & 0.29 & 0.55 & 0.55 & 0.55 & 0.55 \\
$p_{w}\left(\sigma_{w y}=305 \mathrm{MPa}\right)$ & $(\%)$ & 0.00 & 0.29 & 0.00 & 0.00 & 0.00 & 0.00 & 0.29 & 0.00 & 0.00 & 0.00 & 0.00 & 0.00 \\
\hline Min $\left(V_{u 1}, V_{u 2}, V_{u 3}\right)$ & $(\mathrm{kN})$ & 348 & 452 & 348 & 348 & 348 & 348 & 452 & 348 & 709 & 709 & 709 & 709 \\
$V_{b u}$ & $(\mathrm{kN})$ & 236 & 290 & 276 & 298 & 298 & 298 & 290 & 276 & 472 & 628 & 628 & 628 \\
$V_{u}$ (AIJ Guidelines) & $(\mathrm{kN})$ & 236 & 290 & 236 & 236 & 236 & 236 & 290 & 236 & 472 & 472 & 472 & 472 \\
$V_{y}$ & $(\mathrm{kN})$ & 545 & 545 & 545 & 545 & 545 & 545 & 235 & 235 & 1087 & 1087 & 1087 & 670 \\
\hline$V_{\text {exp }}$ & $(\mathrm{kN})$ & 299 & 374 & 375 & 433 & 429 & 406 & 264 & 268 & 599 & 742 & 819 & 625 \\
Failure mode* & & $\mathrm{B}$ & $\mathrm{B}$ & $\mathrm{B}$ & $\mathrm{S}+\mathrm{B}$ & $\mathrm{S}+\mathrm{B}$ & $\mathrm{S}+\mathrm{B}$ & $\mathrm{F}$ & $\mathrm{F}$ & $\mathrm{B}$ & $\mathrm{B}$ & $\mathrm{B}$ & $\mathrm{F}+\mathrm{S}$ \\
\hline$\tau_{b u}$ & $(\mathrm{MPa})$ & 2.35 & 3.24 & 3.24 & 3.74 & 3.74 & 3.74 & 3.24 & 3.24 & 3.45 & 5.49 & 5.49 & 5.49 \\
$\tau_{b u}$ (AIJ Guidelines) & $(\mathrm{MPa})$ & 2.35 & 3.24 & 2.35 & 2.35 & 2.35 & 2.35 & 3.24 & 3.24 & 3.45 & 3.45 & 3.45 & 3.45 \\
$\tau_{b, \text { exp }}$ & $(\mathrm{MPa})$ & 3.42 & 4.09 & 3.99 & 4.55 & 4.34 & 4.63 & 3.72 & 5.16 & 4.14 & 6.70 & 6.08 & 5.55 \\
\hline
\end{tabular}

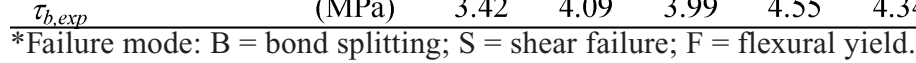



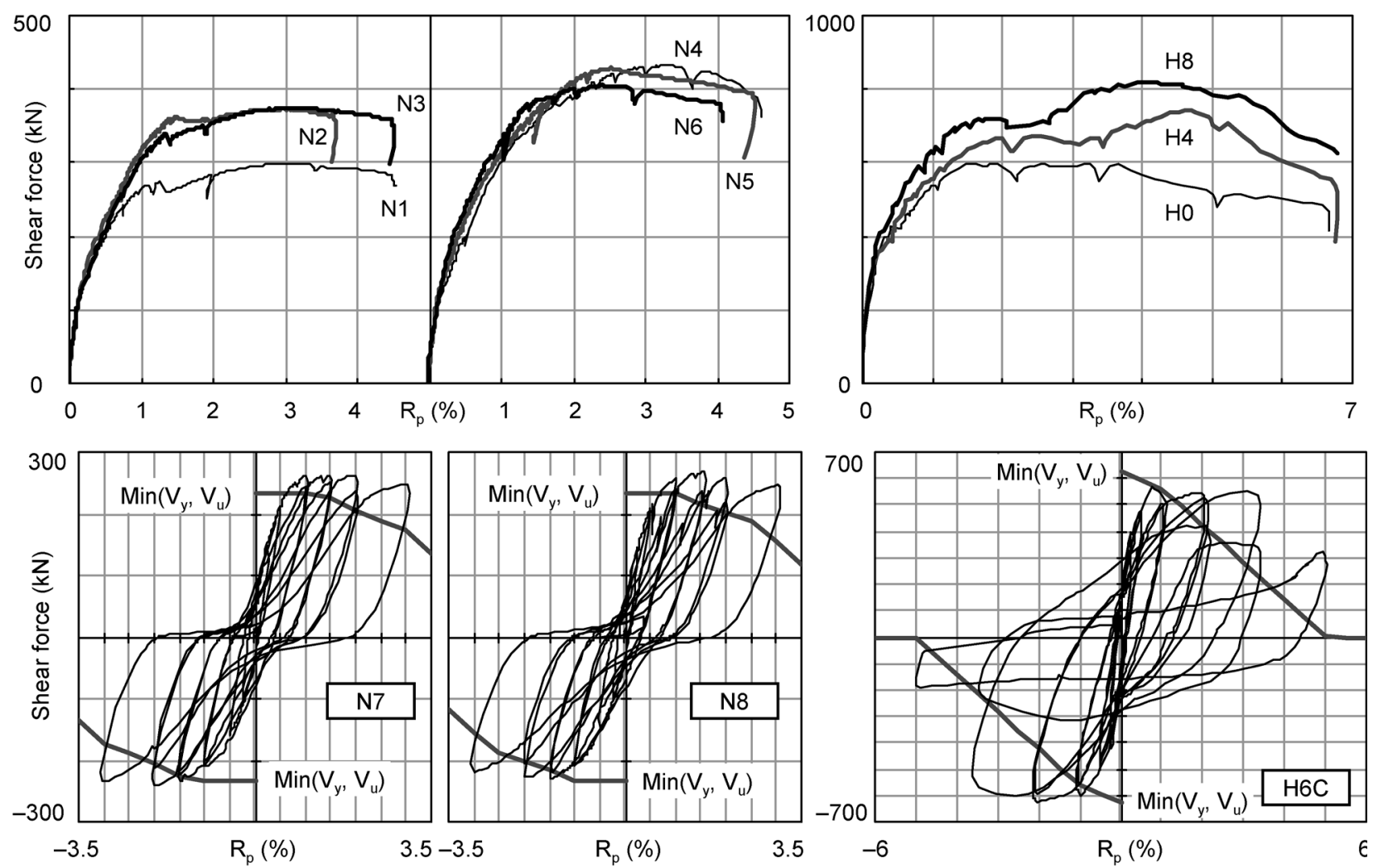

Fig.7. Relationships between Shear Force and Drift Angle

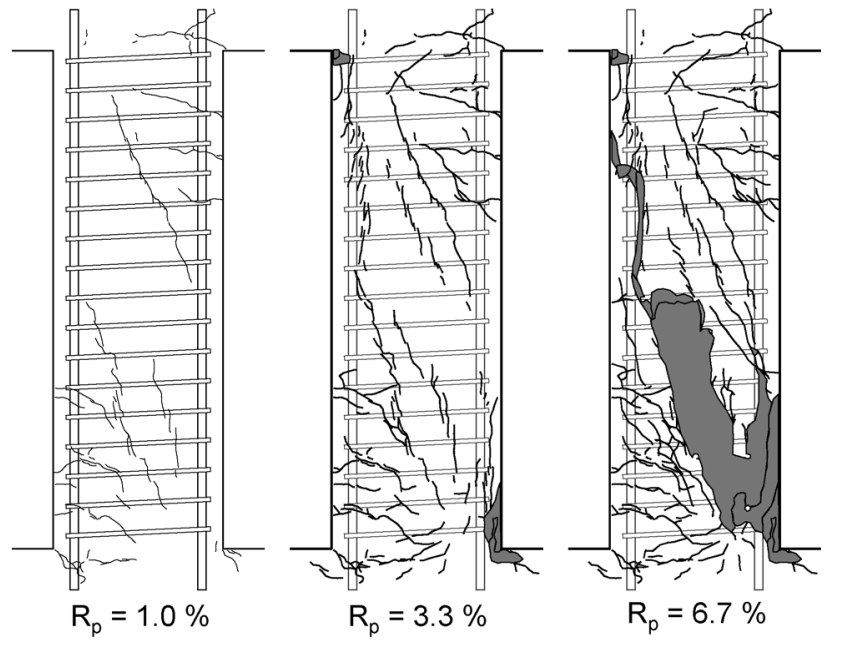

Fig.8. Typical Crack Propagation (Specimen H4)

Table 4 shows the calculated shear strengths of the specimens using Eqs.(1)-(19) and equations presented in the following sections. All the specimens were designed to satisfy $V_{b u}<\operatorname{Min}\left(V_{u 1}, V_{u 2}, V_{u 3}\right)$ in order to estimate the bond strength $\tau_{b u}$ by inducing the bond splitting failure along the flexural bars. Table 4 also presents the shear strength $V_{u}$ according to the AIJ's Guidelines, where contributions of the bondstrengthening hooks were neglected.

\section{Test Results}

Table 4 shows the experimental shear strengths $V_{\text {exp }}$. The $V_{\text {exp }}$ of specimens with the bond-strengthening hooks under monotonic loads (N2, N3, N4, N5, N6, H4 and $\mathrm{H} 8)$ were larger than those without the hooks (N1 and $\mathrm{H} 0$ ) in each test. Figure 7 presents relationships between the shear force and the drift angle. The shear forces remained constant when the drift angle $R_{p}$ exceeded 2 $\%$. At these plateaus, the bond deterioration of flexural bars propagated, inducing splitting cracks along the bars as Fig. 8 shows.

The specimens under cyclic loads maintained a constant shear force after flexural yielding up to a drift angle $R_{p}$ of $3 \%$. Specimens H6C was subjected to a larger $R_{p}^{p}$ up to $5 \%$ and resulted in a significant drop of the shear force.

\section{Bond Stresses}

Strains of the flexural bars measured by the strain gauges were converted into stresses using modified Ramberg-Osgood model (Vecchio 1999). The bond stresses were then computed by difference of the bar stresses between the adjacent strain gauges. Although the bond stresses were not equal between bars in a crosssection, they were averaged in the interest of design practice as adopted in the Guidelines (AIJ 1999). Figure 9(a) presents relationships between the averages of the bond stresses of the flexural bars and the drift angle. For the specimens under cyclic loads (N7, N8 and H6C), only the bond stresses at peak drift angle of every cycle are plotted. The maximum bond stresses are listed in Table 4. 


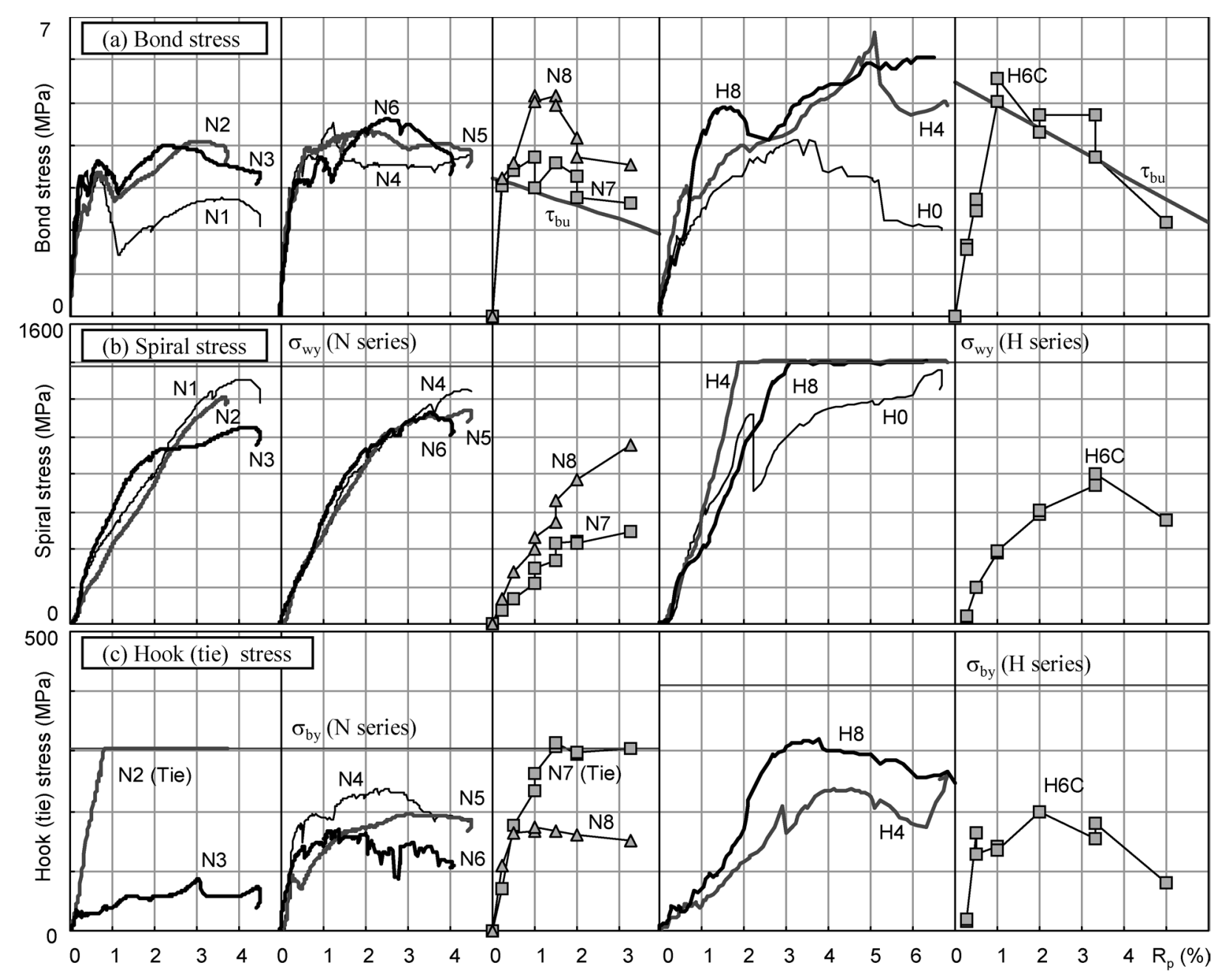

Fig.9. Relationships between Bond Stress, Spiral Stress, Hook (tie) Stress and Drift Angle

The bond stresses remarkably increased in the specimens with the bond-strengthening hooks under monotonic loads (N2, N3, N4, N5, N6, H4 and H8) in comparison with those without the hooks (N1 and H0). The former specimens maintained the same level of the bond stresses even at a large drift angle while the latter showed descending trends of the bond stresses.

Specimens under cyclic loads (N7, N8 and H6C) also presented bond deterioration at drift angle of $1.0 \%$ or larger although the experimental bond strengths $\tau_{b \text {,exp }}(=$ maximum bond stresses) were larger than those of the specimens without the hooks.

\section{Stresses of Spirals and Bond-Strengthening Hooks}

Figure 9(b) shows relationships between the spiral stress and the drift angle. The stresses presented in Fig. 9(b) are maximum values in the span. In all the specimens, spiral stresses exceeded 1,000 MPa and even reached the yield stress in Specimens H4 and H8. Figure 9(c) shows relationships between the bond-strengthening hook stress and the drift angle.

In contrast to the spirals, the hook stresses remained lower than $300 \mathrm{MPa}$ and none of them yielded.

The stress-drift relations were also illustrated in Fig.9(c) for the ties in Specimens N2 and N7, which had yielded.

The above observations indicated that the highstrength spirals functioned as tension-ties in a strut-tie action with a high stress over 1,000 MPa. On the other hand, the hooks improved the bond strength along longitudinal bars, but with a lower stress. The hook shall be made of inexpensive normal strength steel because the induced stress is limited by the anchorage capacity.

\section{Bond Strength}

Figure 10 shows relationships between the experimental bond strength (= maximum bond stress) and total of the reinforcement ratios of the spirals and the bond-strengthening hooks $p_{w}+p_{b}$. The bond stresses increased as the $p_{w}+p_{b}$ increased. However, the bond stress $\tau_{b, e x p}$ of Specimen N6 $\left(p_{w}+p_{b}=1.44 \%\right)$ was lower than that of N8 $(0.58 \%)$, and the $\tau_{b, \exp }$ of H8 (1.54\%) lower than that of H6C (1.29\%). This observation implies a limit of effectiveness of the bond-strengthening hooks.

The hook needs stress-transmitting zones of concrete for anchorage as illustrated in Fig. 11(a). CEB-FIP model code (1978) suggests that a reinforcing bar induces stress to a concrete zone within 7-1/2 bar diameters from the reinforcement. Therefore, over-reinforcement does not 
increase the bond strength because it causes overlap of the adjacent stress-transmitting zones as illustrated in Fig.11(b).

Equation (15) is to be replaced by Eq. (21), which superposes contribution of the bond-strengthening hooks on that of the spirals.

$$
\begin{gathered}
\tau_{\mathrm{s}}=\left\{54+45\left(N_{w}+N_{b e}\right) / N_{t}\right\}\left(b_{s i}+1\right)\left(p_{w}+p_{b e}\right) \\
\text { for } \mathrm{b}_{\mathrm{si}}<\mathrm{b}_{\mathrm{ci}}
\end{gathered}
$$

where

$$
\begin{aligned}
& p_{b e}=\pi N_{b e} d_{b b}^{2} /\left(b_{e} s_{b}\right) \\
& N_{b e}=\min \left[N_{b}, b_{e} /\left(15 d_{b b}\right)\right]
\end{aligned}
$$

Equation (21) considers only the side-splitting mode since the hook aims at prevention of the premature sidesplitting failure. Equation (22) gives the effective ratio of the bond-strengthening hook $p_{b e}$, which is determined by the effective number of the anchors $N_{b e}$. The $p_{b e}$ represents upper limit of amount of the bond strengthening hooks. The diameter of the stress transmission zone is given by 15 times bar diameter as illustrated in Fig. 11(a). This diameter determines the $N_{b e}$ as expressed by Eq. (23). Here the $N_{b e}$ must not be integer. It should be noted that Equations (21)-(23) are available only when anchorage of the bond-strengthening hook is longer than twelve times $d_{b b}$ (AIJ 1986) and inserted deeper than a quarter of the member depth $(D /$ 4).

Solid lines in Fig. 10 indicate the bond strengths calculated by Eqs. (11)-(14), (17) and (21)-(23). The dotted lines indicate those based on AIJ's Guidelines, where the contributions of the hooks were neglected.

For specimens under cyclic loads, the bond deterioration is considered by the factor $\beta$ defined in Eq. (12). The $\beta_{p}$ reduces the bond strength linearly with respect to the drift angle. Figure 9(a) compares the calculated bond strengths of Specimens N7, N8 and H6C with the test results. The calculated strengths of Specimens N7 and N8 are the same. The equations provided good estimates of the descending bond stresses.

\section{Shear Strength Estimation}

Figure 12 compares the experimental and the calculated shear strengths for specimens under monotonic loads. The strengths based on the proposed equations remain constant at $p_{w}+p_{b}$ larger than $0.7 \%$ for $\mathrm{N}$ series and $1.0 \%$ for $\mathrm{H}$ series because of the upper limit of the effective reinforcement ratio $p_{b e}$ of the bondstrengthening hooks defined by Eqs.(22) and (23).

The shear strength of a member under a cyclic load is limited by the flexural capacity and the bond strength. Equations (24)-(27) provide an approximate strength determined by the flexural yielding $V_{v}$ (AIJ 1999):

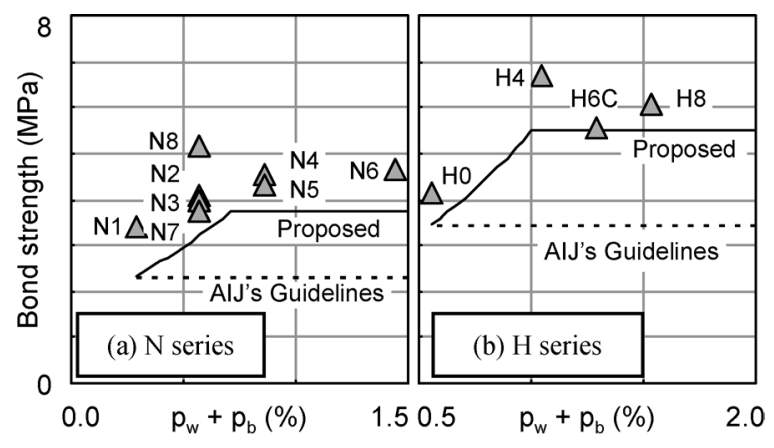

Fig.10. Bond Strength-reinforcement Ratio Relations

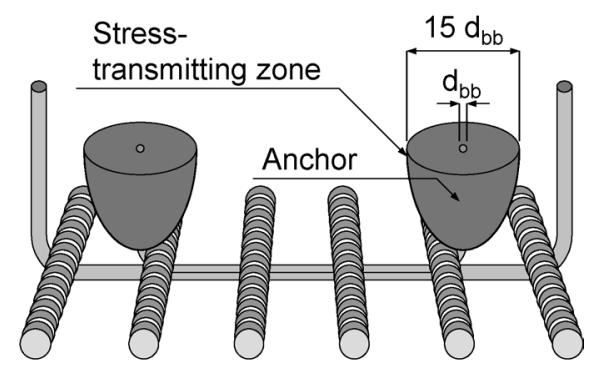

(a) $N_{b}<N_{b e}$

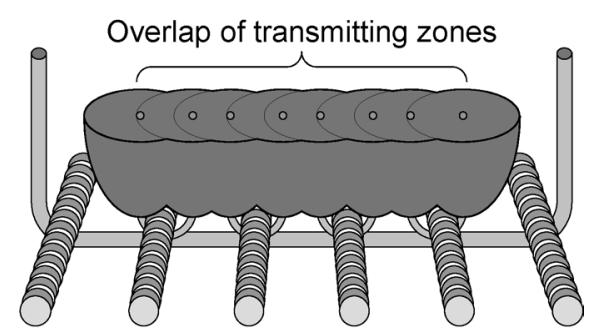

(b) $\mathrm{N}_{\mathrm{b}}>\mathrm{N}_{\text {be }}$

Fig.11. Stress-transmitting Zones of Concrete around Anchors of Bond-strengthening Hooks
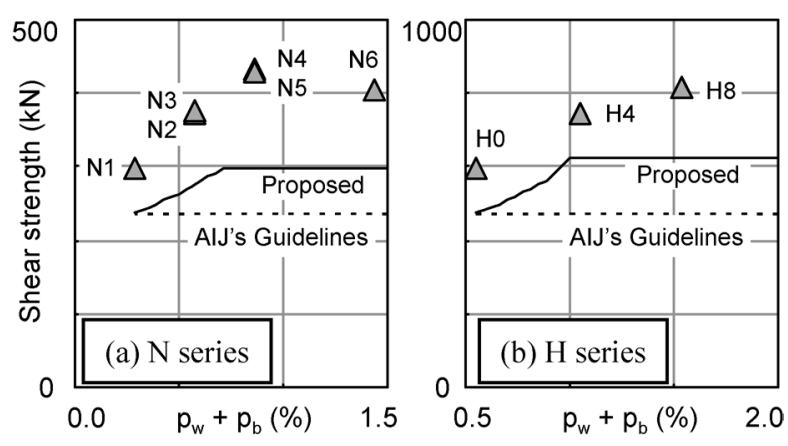

Fig.12. Shear Strength-reinforcement Ratio Relations for Specimens under Monotonic Loads

$V_{y}=2 M_{u} / L$

where

$$
M_{u}=0.9 a_{t} \sigma_{t y} d \quad \text { for } N=0
$$




$$
\begin{aligned}
M_{u}=0.8 a_{t} \sigma_{t y} D+0.5 N D\left\{1-\mathrm{N} /\left(b D \sigma_{B}\right)\right\} & \text { for } N>0
\end{aligned}
$$

The calculated shear strengths for cyclic loading conditions are drawn in Fig. 7. The strengths are limited by the flexural capacity $V_{y}$ in a smaller drift angle, and then begin to decrease because of the bond deterioration.

These calculations provide modest estimates of the shear strengths for both the monotonic and the cyclic loading conditions.

\section{Conclusions}

Effectiveness of the bond-strengthening hooks was investigated through monotonic and cyclic loading tests of twelve RC specimens, which consisted of 1,300 MPaclass spirals. The anchor length of the hook $l_{b}$ was twelve times the hook diameter $\left(12 d_{b b}\right)$, and the anchors were inserted deeper than a quarter of the member depth $(D /$ 4). The following remarks were made based on the test results:

(1) The proposed bond-strengthening hooks increased the bond strengths along flexural reinforcing bars and the shear strengths of members. The specimens maintained the shear strengths at least up to drift angle of $3 \%$ even under cyclic loads.

(2) Effectiveness of the bond-strengthening hook was limited because the anchor of the hook needed stresstransmitting zone of concrete. Diameter of this zone was assumed to be 15 times the hook diameter according to CEB-FIP model code.

(3) Proposed modifications for the equations of the AIJ's Guidelines provided modest estimates of the shear strength of the strengthened members for both the monotonic and the cyclic loading conditions.

The authors' grateful appreciation goes to Professor B. Tsuji, Associate Professor M. Nishiyama of Kyoto University. Neturen Corporation is acknowledged for financial support and providing the testing materials.

\section{References}

1) AIJ (1986) Recommendation for Detailing and Placing of Concrete Reinforcement. AIJ, 13-17.

2) AIJ (1999) Design Guidelines for Earthquake Resistant Reinforced Concrete Buildings Based on Inelastic Displacement Concept. AIJ, 138-192.

3) CEB-FIP (1978) Model Code for Concrete Structures. CEB-FIP International Recommendations, 3rd edition, Comité EuroInternational du Béton, Paris, 155-160.

4) Kamitani, K. et al. (2002) Hook-Shaped Reinforcement for Bond Splitting Prevention in RC Beams. Summaries of Technical Papers of Annual Meeting, AIJ, C-2, 289-292.

5) Sato, Y. and Fujii, S. (2002) Local stresses and crack displacements in reinforced concrete elements. Journal of Structural Engineering, ASCE, 128(10), 1263-1271.

6) Sato, Y. et al. (2003) Buckling of longitudinal bars of RC columns strengthened with continuous fiber sheet. Proceedings of the Japan Concrete Institute, 24, 2036.

7) Vecchio, F., J. (1999) Towards Cyclic Load Modeling of Reinforced Concrete, ACI Structural Journal, 96(2). 193-202. 